\title{
Restructuring Ceramic Production for Wealth Creation, Security and Sustainable Development through the Construction of Kick Wheel
}

\author{
Sunday Esosuakpo \\ http://dx.doi./org/10.4314/ujah.v21i4.7
}

\begin{abstract}
Right from the time of independence, Nigeria has adopted different restructuring methods in order to create wealth that will improve her economy, ensure security and enhance sustainable development. In doing this, different aspects of human and natural resources have been explored. But it appears that ceramics which is a branch of industrial art and an aspect of the people's culture has not been considered even when the major raw material (clay) required is abundantly available as the oil. Perhaps, its non-consideration could be due to the crude tools used which do not give room for mass production of ceramic wares that could generate wealth to the nation and her citizens, ensure security and enhance sustainable development in Nigeria. Therefore, this paper explores restructuring ceramic production for wealth creation, security and enhancement of sustainable development in Nigeria through the construction of kick wheel. In carrying out the construction, materials were sourced and constructed into parts. Thereafter, assemblage was done through welding and screwing of parts. In a trial test, the kickwheel worked effectively in mass production of ceramic wares that could create wealth and make ceramics interesting for people to take up as job, thus reduce idleness and crime and ensure peace and security. The paper recommended among others that our country should establish centres for local constructions and fabrications as it will help in turning out our own Nigerian made tools and equipment, give room for apprenticeship, facilitate establishment of cottage industries, help revamp and restructure moribund industries, create wealth, and enhance security and sustainable development in Nigeria.
\end{abstract}


Keywords: Restructure, National Development, Construction, KickWheel, Ceramics, Wares, Wealth Creation

\section{Introduction}

In every sector, society, organisation or country, restructuring is always carried out. The purpose is vied towards overall development. Nigeria, as a developing nation at one time or the other carry out restructuring with the hope to improve the economy, create wealth for the nation and her citizens, ensure peace and security and attain sustainable development. In the bid to actualize the above objective, all sectors of human and natural resources are being explored. However, ceramics which is also known as pottery that is an aspect of industrial art and part of the people's culture has not been given maximum attention even when the major raw material required (clay) is abundantly available in Nigeria.

Ceramics by its industrial nature and the availability of clay can influence the establishment of ceramic industries and cottage industries that could create job, remove people from idleness, provide income to people and reduce abject poverty, and thus create an atmosphere of security and enhance the nation's development. Perhaps, this has not been plausible because our country do not have her indigenous technology that can provide the necessary tools and equipment that can facilitate the establishment of ceramic industries and therefore still depend on foreign industries. Now, the question is, how long will this continue? Shall we continue to fold our hands without embarking on construction as a measure to provide tools and equipment for processing our raw materials into finished goods and be of wealth or economic value to the nation? No wonder Fajuyigbe (2011:88) asked that for how long will our country continue to depend on foreign products and long will it take us as a people to have a shift from consumer mentality to producer mentality. 
In reaction to the above, Egonwa (2007:10) noted that Nigerian art tradition should respond to other social variables such as education, technology, economy and others. Therefore, the objective of this paper is to construct a kick-wheel that can restructure the ceramic sector or industry for high productivity, thus create wealth to the nation and her citizens, provide job and remove people from idleness thereby curbing crime and consequently ensuring peace, security and sustainable development It is also aimed at encouraging local construction of tools and equipment as it will make our nation have her indigenous technology whose maintenance will also be easy when the need arises, provide employment, create wealth, reduce crime and ensure security in Nigeria.

\section{The Concept Kick-Wheel}

Ceramics is a branch of fine and applied arts that is concerned with the production of wares from clay and subjecting them to heat treatment for permanence. In producing ceramic wares, some basic methods such as pinch, coil and slab are used. In adopting any of these methods require some kind of simple tools which do not give room for mass production of wares. But in the quest for mass production, other methods such as casting, jigger and jollying throwing emerged. With the emergence of these methods and the effect of technology, sophisticated equipment among which is the wheel of all types and their common name is potter's wheel was invented.

The potter's wheel is an equipment that enables a Ceramist or Potter to shape a ball of clay into a cylindrical ware. It is an equipment for skilful manipulation of a lump of clay into a light weight hollowed cylindrical ware and using it in the production of ware or wares is known as throwing. Onu (2006:27) regarded the potter's wheel as a rotating mechanical device with a flat disk head connected by a rotating shaft to the fly wheel which facilitates the 
manipulation of lumps of clay into spherical hollowed and flat forms through the process of "throwing". He further stated that the kick wheel is operated by foot power and to do this, momentum is built up and maintained while throwing through the kick bar or treadle. He added that, what probably led to the invention of the potter's wheel was the search for a device that could reduce the stress of moving round the pot during production.

In explaining the term potter's wheel, Speight and Toki (2004:245) said that the potter's wheel was developed over centuries and it evolved from the many types of turn tables that potters used throughout the world to rotate their hand built pots in other form and smooth them evenly. In describing its operation, they noted that the potter's wheel must spin at a speed of at least one hundred (100) rotations per minute (rpm) and below that speed, the centrifugal force responsible for the fast rising of the clay wall in the potter's hands will not operate effectively. In stating what the potter's wheel is, Akinbogun and Kashim (2006:75) noted that, it is a spinning machine for shaping circular forms. Hagger (1959) in Akinbogun and Kashim (2006:75) observed that it is the most important tool of the potter. Potter's wheels are of different types with different modes of operations. Examples are electric wheels, slave and master and kick wheel which is the focus of this paper.

The kick-wheel is a kind of potter's wheel that is manually powered through peddling. It is a ceramic equipment for shaping a ball of clay into cylindrical wares through peddling or kicking thus, spinning the wheel head. It is a wheel that is manually operated and kept in motion during ceramic production by kicking a pedal connected to a shaft which spins the shaft and a flat plate known as wheel head attached to it. In explaining the advantages of working with the kick-wheel, Speight and Toki (2004:248) noted that the action of kicking the wheel results in the transfer of movement to the other parts of the body including your arms. Also in stating what kick 
wheel is, Wikipedia, (n.d) who said that in pottery, a potter's wheel is a machine for shaping (known as throwing) of round ceramic ware. In stating other functions of the wheel, it noted that the wheel may be used during the process of trimming the excess body from dried ware, and for applying incised decoration or rings of colour.

\section{Materials Used for the Construction of the Kick Wheel}

1. $10 \mathrm{~mm}$ mild steel Angle iron

2. Air-cool electrical generator Fly Wheel

3. 911 lorry starry pipe

4. $16 \mathrm{~mm}$ mild steel metal rod

5. 1Omm mild steel metal pan

6. Galvanized pipe

7. Mild steel metal pan

8. 6204 industrial bearing

9. 14 and 17 sized bolts washers and nuts

10. Gloss paint

Construction of Parts and the Kick-wheel for Ceramic Production

The frame

Figure 1.The frame

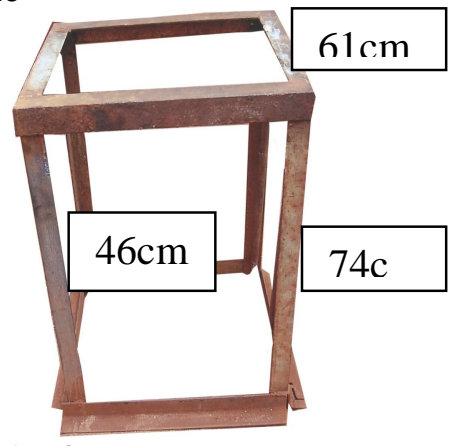


The frame is made with mild-steel metal angle iron firmly welded together in such that it will be able to carry the weight of all other parts that will be attached to it. It has the same mild steel angle iron re-enforcement at the bottom which holds the four legs together and also serve as bass stand. On the reverse side of one of the angle irons on the top of the frame, two metal rings for holding the kick pedal are attached. The frame is rectangular in shape and measures $46 \mathrm{~cm}$ by $61 \mathrm{~cm}$ and $74 \mathrm{~cm}$ in height.

\section{The flywheel}

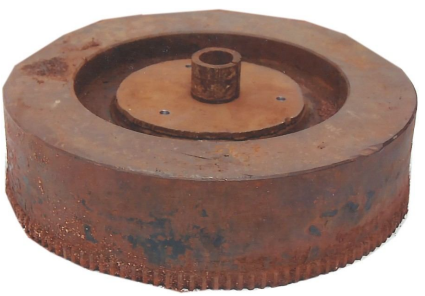

Figure 2. The flywheel

The flywheel is an originally made flywheel for air-cool diesel electrical generator. It was found worthy and adapted for the construction because of its weight. . But in line with the opinion of Njami (2006) who said, "Creation involves re-creation and destroying in other to reconstruct". Therefore, in other to reconstruct it to serve as part of the kick-wheel, a thick flat pan measuring $18 \mathrm{~cm}$ in diameter with three holes on the side for screwing with a $9 \mathrm{~cm}$ in height mild steel metal ring is constructed and forced into the hole in the centre of the flywheel. This is done in other to reduce the size of the hole to the size of the shaft that will be passed across. On the side of the mild steel metal ring, there is a threaded hole on which a constructed butterfly-shaped screw both is attached. The butterfly-shaped both is to hold the shaft in place to avoid wobbling. The fly wheel measures $39 \mathrm{~cm}$ in diameter and $11 \mathrm{~cm}$ in height. 


\section{The Shaft}

\section{Figure 3. The shaft}

The shaft is made with a mild steel metal constructed using 911 lorry starry pipe. At both ends, it is threaded after lathe machine was used to evenly reduce a small part of it in such that one end will hold the wheel head while the other side will be able to hold the connecting rod thereby joining the kick pedal and the shaft. On the centre of the shaft, a metal ring which serve as seating or stopper for the fly-wheel is attached

\section{The kick-pedal}

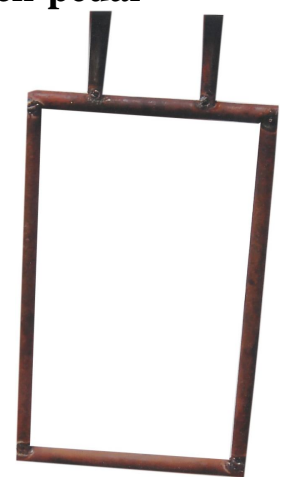

Figure 4. The kick pedal

The kick-pedal is made is made with metal pipe strongly connected together through welding. Prior to its welding, a sixteen millimetre 
metal rod was passed through each of the holes in the four pipes used and was first of all welded together inside at the four joints before welding the pipe outside. This is done in other to re-enforce the kick pedal to enable it pressure during kicking or peddling. The kick pedal has two pipes with a threaded stainless steel iron welded at the top for hanging on the two metal rings in the frame and it is rectangular in shape. It measures $30 \mathrm{~cm}$ by $60 \mathrm{~cm}$.

\section{The industrial bearing}
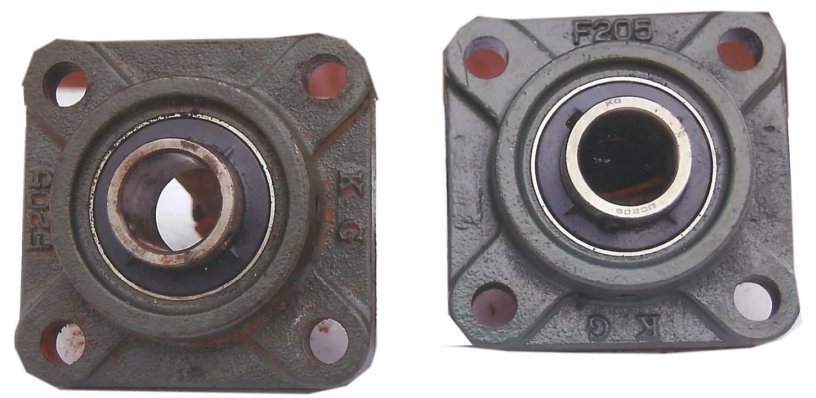

Figure 5. The two industrial bearings

To facilitate smooth spinning of the kick wheel, two 6204 industrial bearings are used. This makes it easy to rotate the flywheel which inturn rotates the wheel head easily even under a small kick thus reducing the exertion of much energy during throwing. 


\section{The Wheel-head}

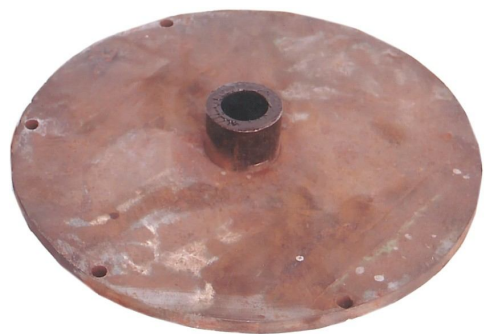

Figure 6. The Wheel head

The Wheel-head is made with $10 \mathrm{~mm}$ thick mild steel metal pan. It measures $25 \mathrm{~cm}$ in diameter. On the centre of the pan, a small round groove was created with lathe machine and thereafter a small threaded mild steel pipe measuring $3 \mathrm{~cm}$ in height is driven into it while the outside is re-enforced through welding.

\section{Assembling of Constructed Parts to form the Complete Kick- wheel}

The assembling of the constructed parts to form the complete kickwheel is done in the following steps.

\section{Fixing of the kick pedal on the frame}

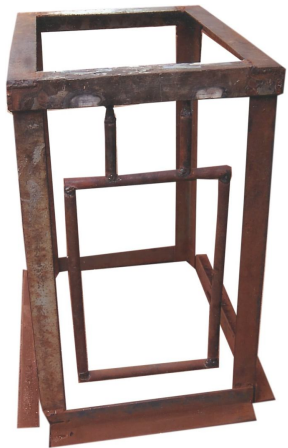

Figure 7. The kick pedal fixed on the frame. 
Step I. The kick pedal is fixed on the frame through the metal rings on the reverse side of one of the angle irons on top of the frame as shown in the figure above. Grease is applied in other to check friction and corrosion.

Assembling of one industrial bearing, shaft, and fly wheel and connecting pan.

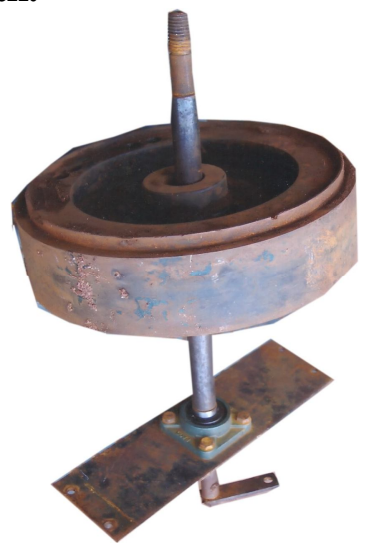

Figure 8. Assembled industrial bearings, shaft, fly wheel and connecting pan.

Step II. In assembling this component part as shown above, one of the industrial bearing is screwed on a U-shaped channel serving as seating for the bearing and a cross bar. The shaft is passed across it at the bottom. Also, a connecting pan is screwed on it using fourteen sized bolt and washer from the bottom. Thereafter, the shaft is passed through the hole in the flywheel taking its rest on the metal ring serving as stopper. 


\section{The fly wheel, shaft, industrial bearing and connecting rod fixed on the frame.}

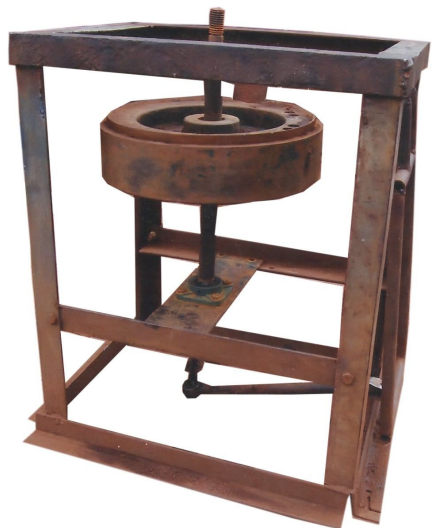

Figure 9. The fly wheel, shaft, industrial bearing and connecting rod fixed on the frame.

Step III. Having assembled the fly wheel, shaft, one industrial bearing and the connecting pan, two angle irons were screwed on the frame and it is on them that the U-shaped channel serving as cross bar caring the fly wheel and other parts that make-up that component is fixed using seventeen sized bolts, washers and nuts. To connect the shaft and the kick pedal together, peugout bore joint and its rod is screwed on the pan fixed on the bottom of the shaft which makes it easy to spin the fly wheel and the wheel-head when kicking.

\section{Fixing of top pan and the wheel head}

The Complete kick Wheel 


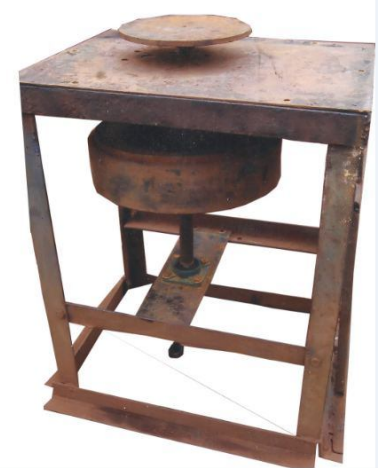

Figure 10. The Complete Kick Wheel

Step IV. The last stage of assembling is the coverage of the frame on top with metal pan and the screwing of the wheel head. But prior to the coverage, a hole which the shaft passed through is created on the centre of the pan with four small ones which the second industrial bearing is screwed on using bolts and nuts.

\section{Painting of the Kick Wheel}

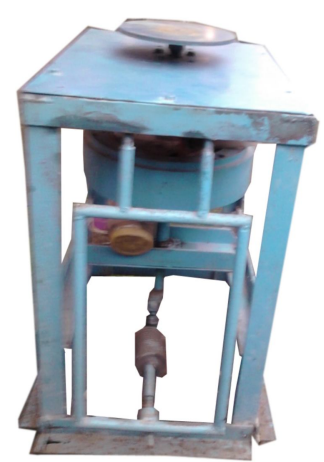

Figure 11. The Kick wheel after painting 
Every metal work is prone to corrosion. Therefore, to check corrosion and enhance aesthetic value, the constructed kick wheel is painted using gloss paint while the bore joint is covered with bore joint plastic cover to protect it from sand and water that may cause damage during usage.

\section{Construction of the Kick Wheel for Wealth Creation, Security and Development}

One of the main goals of our country, Nigeria as stated in the national policy on Education (2004:6) is to make Nigeria "a united, strong and self-reliant nation". To make Nigeria self-reliant at this time means looking beyond oil. Considering this goal along with the abundant natural endowment (clay), Nigeria would have had a lot of functional ceramic industries, cottage industries and pottery centres if there are tools and equipment. Then, the outcome would have yielded wealth and create wealth to the nation and her citizens, provided good atmosphere for economic, infrastructural and entrepreneurial development, enhance security and development.

Wealth refers to the amount of physical cash and properties that an individual or a nation poses. While wealth creation is a means or strategy put in place by an individual or nation with a view to money or something of economic value that will improve standard of living, enhance security and for infrastructural development. The Oxford Advanced Learner's Dictionary defined the term wealth as a large amount of money, property that a person or country owns; the purpose of industry to create wealth. For any strategy to be put in place for the purpose of wealth or wealth creation, appropriate tools and equipment are required. Therefore, the construction of the kick wheel being an equipment for ceramic production is of wealth and wealth creation through the following ways and their consequent shall be security and development. 


\section{Enhanced Ceramic Production}

One of the factors that make up the wealth of an individual or a nation is the products made and their rate of production. It is also obvious that the standard of living of people, economy or wealth, level of peace and security and infrastructural development of a nation is determined by what they produce and the rate of production. The kick wheel constructed serve as an industrial equipment as it facilitates mass production of wares because it is manually powered by pedalling or kicking and devoid of electrical encumbrances. With the kick wheel, ceramic wares can be made available for sale in our markets, stores thus meeting the demands of consumers. It is also an addition in Nigerian made products which can be counted as part of the wealth of the nation and citizen who engages in ceramic production.

\section{Sales of Ceramic Products}

Buying and selling is part of human and a nation's daily activity. It is a means through which needs are met, wealth is made and creating wealth. Ceramic products produced form the kick wheel can provide avenue for people to be engaged in sales either on wholesale or retail bases and be economically empowered. Individuals or Nigeria as a country can make wealth from sales of ceramic products either within the country or through exportation. No wonder Ekong (2007:4) opined that Nigerian economy cannot afford to rely so much on oil since it may be dangerous to leave ones eggs in just one basket. Therefore, embarking on the production and sales of ceramic wares becomes diversification of our nation's source of income.

\section{Enhanced Indigenous Technology}

Any nation like Nigeria that is naturally endowed with abundant raw materials and do not have her indigenous technology that can refine or process them into well finished goods will end up exporting raw 
materials and import finished goods. This practice does not make such country to have total control of their resources or raw materials. In most cases, some raw materials are left untapped or under-utilized. This is the case of clay in Nigeria which does not give room for wealth or economic development and industrial growth. Akinbogun and Kashim (2006:72) observed that for a country to grow and join the league of industrialized nations, her industrial sector, based on modern technology must be well developed. They further stated that, the returns from the industrial sector if fully developed would not only help to propel the economic status of the country but would also enhance the political power of such a nation among other nations. Therefore, the constructed kick wheel does not only facilitate production of ceramic wares for wealth generation but it is an addition in the field of ceramic technology in Nigeria.

\section{Health Benefits of the Kick-wheel}

Health as it is commonly said is wealth. To buttress this statement, Achebe 1984 in Ogelenya and Kemi (2017:24) asserts that, while praying in a traditional African setting, a man prays that they do not ask for wealth because he that has health and children will also have wealth. The kick-wheel being an equipment for ceramic or pottery production is also an equipment for physical and mental exercise. In kicking the wheel when producing wares, the legs, waist, hands, brain and other parts of the body are exercised and co-ordinated to produced not just what the Ceramist or Potter has in mind but what will be of market value. Through this, income and wealth can be made.

\section{Conclusion}

For wealth, wealth creation, peace and security and sustainable development to be achievable especially in a country like Nigeria that has so much natural endowment, it is necessary for all citizens to 
engage in construction or fabrication of tools and equipment. Through this, indigenous technology can be achieved, tools and equipment that will enable us process our raw materials into finished goods will be made, income can be generated, many people or citizens will be engaged in productive ventures, crime will be reduced and national security will be a reality.

\title{
Recommendations
}

The government through the ministry of education and youth should establish construction centres in schools at all level and in every local government area. This will help to make the study of introductory Technology as a subject more encouraging, interesting to students and youths in communities can also learn through apprenticeship and be productive.

Youths and unemployed young graduates should engage in construction as a way of creating self-employment and income generation. Even those employed in their spare times should also embark on construction as a measure of generating additional income.

Wealth cannot be made if people do not look within their environment or county to discover their untapped resources or raw materials and put them into use. Therefore, government or individuals in collaboration with government should explore our environment for raw materials that can locally be refined into finished goods. This will make avenue for income or wealth.

Government should make found available for construction as it will make people to be encouraged to take up construction as an occupation.

\author{
Sunday Esosuakpo, PhD \\ Department of Fine and Applied Arts \\ Delta State College of Education, Agbor
}




\section{References}

Akinbogun, T.L. \& Kashim I.B. (2006). Issues I Setting up Cottage

Ceramic Businesses: A Focus on Ondo and Ekiti States.

Ashakwu Journal of Ceramics. Vol.3

Egonwa, O.D. (2007). Writing About Art and Making Art in Nigeria:

Many Legs How Much Movement? $14^{\text {th }}$ in the series of

Inaugural Lectures of Delta State University, Abraka. p.10

Ekong, C.E. (2007). Economic Empowerment through Ceramic Beads Production in Nigeria. Ashakwu Journal of Ceramics. Vol.4 No.2.

Fajuyigbe, M.O. (2011). Actualising the Millennium Development Goals in Nigeria, Prospects and Challenges of the ceramic industry. Ashakwu Journal of Ceramics. Vol.8. p.88.

Federal Republic of Nigeria (2004). National Policy on Education. Lagos; Nerdc

Njami, S. (2006). Introduction to African Contemporary Art.

Retrieved from

http://africanpainters.blogspot.comm/2006/11/introduction-toafrican-contemporary.html.

Ogelenya, G. \& Kemi, A.A. (2017). Ujamaa as a Framework for African Development. Abraka Humanities Review. A Journal of the Faculty of Arts, Delta State University, Abraka. Vol. 7 No.3.

Onu, C.C. (2006). Fabrication of Cost-effective Crank kick-wheel. Ashakwu Journal of Ceramics. Vol.3

Oxford Advanced Learner's Dictionary (2010). Wealth. New York. Oxford University Press

Speight, F.C. \& Toki, J. (2004). Hands in Clay; $5^{\text {th }}$ Edition. New York; McGraw Hill

Wikipedia (n.d) Potter's Wheel. Retrieved from https//en.mwikipedia.org>wiki 